\title{
Seleno-Amino Acids in Vegetables: A Review of Their Forms and Metabolism
}

\author{
Jiangtao Hu', Zheng Wang', Li Zhang', Jie Peng', Tao Huang ${ }^{1}$, Xiao Yang ${ }^{1 *}$, \\ Byoung Ryong Jeong ${ }^{2,3,4}$ and Qichang Yang ${ }^{1 *}$
}

\begin{abstract}
'Institute of Urban Agriculture, Chinese Academy of Agricultural Sciences, Chengdu National Agricultural Science and Technology Center, Chengdu, China, ${ }^{2}$ Division of Applied Life Science (BK21 Four), Department of Horticulture, Graduate School of Gyeongsang National University, Jinju, South Korea, ${ }^{3}$ Institute of Agriculture and Life Science, Gyeongsang National University, Jinju, South Korea, ${ }^{4}$ Research Institute of Life Science, Gyeongsang National University, Jinju, South Korea
\end{abstract}

OPEN ACCESS

Edited by:

Zhi-Qing Lin,

Southern Illinois University Edwardsville, United States

Reviewed by:

Miguel Mourato,

University of Lisbon, Portugal

Szilvia Veres,

University of Debrecen, Hungary

*Correspondence:

Xiao Yang

yangxiao@caas.cn

Qichang Yang

yangqichang@caas.cn

Specialty section:

This article was submitted to

Plant Nutrition,

a section of the journa

Frontiers in Plant Science

Received: 29 October 2021 Accepted: 10 January 2022 Published: 02 February 2022

Citation:

Hu J, Wang Z, Zhang L, Peng J,

Huang $T$, Yang $X$, Jeong $B R$ and Yang Q (2022) Seleno-Amino Acids in Vegetables: A Review of Their Forms and Metabolism.

Front. Plant Sci. 13:804368. doi: 10.3389/fp/s.2022.804368
Seleno-amino acids are safe, health-promoting compounds for humans. Numerous studies have focused on the forms and metabolism of seleno-amino acids in vegetables. Based on research progress on seleno-amino acids, we provide insights into the production of selenium-enriched vegetables with high seleno-amino acids contents. To ensure safe and effective intake of selenium, several issues need to be addressed, including (1) how to improve the accumulation of seleno-amino acids and (2) how to control the total selenium and seleno-amino acids contents in vegetables. The combined use of plant factories with artificial lighting and multiple analytical technologies may help to resolve these issues. Moreover, we propose a Precise Control of Selenium Content production system, which has the potential to produce vegetables with specified amounts of selenium and high proportions of seleno-amino acids.

Keywords: plant factory, precise control, selenium metabolism, seleno-amino acids, vegetables, mushrooms

\section{INTRODUCTION}

Selenium (Se) is an essential trace element for human health. For adults ( $\geq 18$ years), the recommended nutrient intake (RNI) of Se for both genders in Chinese populations is $60 \mu \mathrm{g}$ per day (National Health Commission, 2018). Appropriate Se supplementation has been reported to exert anti-viral effects, reduce the levels of thyroid autoantibodies, and decrease the risk of cardiovascular disease, type 2 diabetes, and Keshan and Kashin-Beck diseases (Stranges et al., 2007; Rees et al., 2013; Wichman et al., 2016; Liu et al., 2018; Muzembo et al., 2019; Zhang et al., 2019a). However, 500 to 1,000 million people worldwide consume less or more than the recommended levels of Se (Shreenath et al., 2018). Both excessive and deficient intake of Se are associated with health risks. Dietary deficiency of Se in humans is associated with an increased risk of death, hypoimmunity, and cognitive decline (Rayman, 2012), while excess Se supplementation may cause toxicity as Se is involved in the generation of reactive oxygen species and oxidation of thiol compounds, which can lead to oxidative damage in cells (Rayman et al., 2018; Pyrzynska and Sentkowska, 2021). Therefore, a suitable dietary source of Se supplementation containing appropriate levels of this element could be beneficial for human health. 
The main sources of Se in the diet are meats and cereals, which contribute more than $50 \%$ of the total dietary Se intake in the British and Chinese populations (Gao et al., 2011; Rayman, 2012; Yu et al., 2015). Vegetables and fruits only contribute around $7 \%$ of the total dietary Se intake in the British and Chinese populations (Rayman, 2012; Yu et al., 2015). Indeed, vegetables are recognized as relatively weak sources of dietary Se, as they generally contain less than $0.1 \mu \mathrm{gg}^{-1}$ fresh matter (FM) of Se (Rayman, 2012). However, some species of vegetables are Se accumulators, such as Brassicaceae vegetables, garlic, and onions (Finley, 2005). For instance, garlic can accumulate more than $1,300 \mu \mathrm{gg}^{-1}$ dry matter (DM) of Se, with $73 \%$ in the form of $\gamma$-glutamyl-Se-methylselenocysteine ( $\gamma$-Glu-MeSeCys; Ip et al., 2000). Considering their relatively high consumption, rapid growth (less than 30 days for harvest of leafy greens), and ability to accumulate Se, vegetables hold great potential as Se-fortified sources for dietary Se intake.

Seleno-amino acids (Se-AAs) are organic forms of Se and are thus thought to be ideal chemical forms for Se supplementation. Organic forms of Se have been reported to be lower in toxicity compared to inorganic Se. Vinceti et al. (2017a) reported that consumption of approximately $260 \mu \mathrm{g}$ per day organic Se led to toxic effects; the corresponding value for inorganic Se was $16 \mu \mathrm{g}$ per day for humans. Vinceti et al. (2017b, 2018) reported that overexposure to inorganic Se was associated with Alzheimer's dementia, neurodegenerative diseases, amyotrophic lateral sclerosis, and Parkinson's disease. Moreover, dietary organic Se has high bioavailability because most of them can reach the systemic circulation from the gastrointestinal tract and can promote its action in the exposed organism. Previous studies reported that $70-90 \%$ of Se in Se-enriched plant foods could be transformed into organic forms and distribute and function in human organs and tissues (Pyrzynska and Sentkowska, 2021). Among the various Se-AAs, selenomethionine (SeMet) has the highest bioavailability of more than $90 \%$, which is 1.5 times higher than that of selenite (Burk and Hill, 2015; Xie et al., 2021). In vitro simulated gastrointestinal digestion studies suggested SeMet is the major form of bioaccessible Se released from food matrices (Bhatia et al., 2013; Wang et al., 2013; do Nascimento da Silva et al., 2017). Overall, due their abundance in vegetables, low toxicity, and high bioavailability, Se-AAs are thought to be valuable forms of dietary Se supplements. In this regard, it is of interest to develop Se-enriched vegetables with high-Se-AA contents to ensure safe, sufficient intake of Se.

In this review, we critically explore the literature related to the forms of Se-AAs and Se concentrations of different vegetables, the factors that affect Se speciation, and the metabolism of Se-AAs in plant species. This comprehensive review may aid the innovation and development of Se-enriched vegetables with high-Se-AA contents in agricultural practice.

\section{VEGETABLES AS DIETARY SUPPLEMENTS OF Se}

\section{Se-AA Forms and Concentrations in Different Species of Vegetables}

Vegetables can biotransform inorganic Se into Se-AAs, such as SeMet, selenocysteine (SeCys), Se-methylselenocysteine (MeSeCys), and $\gamma$-Glu-MeSeCys (Figure 1). These Se-AAs can be almost completely absorbed by human organs and are beneficial for human health.

We reviewed the concentrations of total Se and the main Se-AAs in the edible parts of vegetables and mushrooms biofortified with Se (Table 1). The main Se-AAs in vegetables exhibit species-specific patterns, regardless of the Se source and application method. Vegetables belonging to the Brassicaceae and Liliaceae families predominantly accumulate MeSeCys,
A<smiles>C[Se]CC[C@H](N)C(=O)O</smiles>

Selenomethionine<smiles>N[C@@H](C[SeH])C(=O)O</smiles>

C

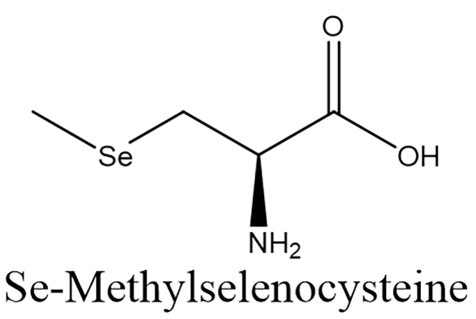

D

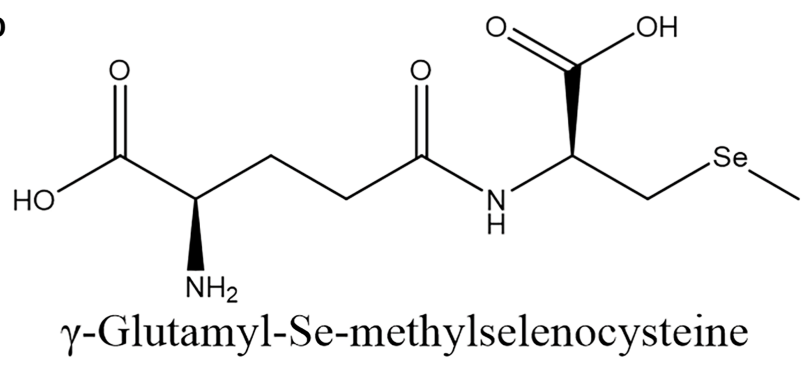

FIGURE 1 | Structures of seleno-amino acids commonly found in vegetables. (A) SeMet; (B) SeCys; (C) MeSeCys; and (D) $\gamma$-Glu-MeSeCys. 
TABLE 1 | Concentrations of total selenium and the main seleno-amino acids in the edible parts of vegetables and mushrooms biofortified with selenium.

\begin{tabular}{|c|c|c|c|c|c|c|}
\hline Family & Common name & Se source and dose & Application method & $\begin{array}{l}\text { Total Se } \\
\text { concentration }\left(\mu \mathrm{gg}^{-1}\right)\end{array}$ & $\begin{array}{l}\text { Main Se-AAs and } \\
\text { concentration } \\
\left(\mu \mathbf{g g}^{-1}\right)\end{array}$ & Reference \\
\hline Agaricaceae & Mushroom & $N G$ & $N G$ & 9.15, DM & SeCys, 5.73, DM & Hu et al., 2021b \\
\hline Agaricaceae & Mushroom & $\begin{array}{l}\text { Nanoparticles, } 10 \mu \mathrm{gg}^{-1} \\
\text { substrate }\end{array}$ & Substrate application & About 10, DM & SeMet, 2.01, DM & Hu et al., 2021a \\
\hline Agaricaceae & Mushroom & $\begin{array}{l}\text { Selenite or selenate, } \\
\leq 5 \mu \mathrm{gg}^{-1} \text { substrate }\end{array}$ & Substrate application & 5.32 or $3.36, \mathrm{DM}$ & SeMet, NG & Zhou et al., 2018 \\
\hline Agaricaceae & Mushroom & Selenite, $6.4 \mu \mathrm{M}$ & Substrate application & 23.1-31.0, DM & SeMet, 17.1-23.1, DM & $\begin{array}{l}\text { Milovanovic et al., } \\
2019\end{array}$ \\
\hline Agaricaceae & Mushroom & $\begin{array}{l}\text { Selenite or selenate, } \\
1.2 \mathrm{mM} \text { or } 26.5 \mu \mathrm{M}\end{array}$ & Substrate application & 111.8 or $45, \mathrm{DM}$ & $\begin{array}{l}\text { SeMet, } 55.1 \text { or } 24.3 \text {, } \\
\text { DM }\end{array}$ & Hu et al., 2020 \\
\hline Agaricaceae & Mushroom & Selenite, $5 \mu \mathrm{gg}^{-1}$ substrate & Substrate application & 59.6, DM & SeMet, 33.9, DM & Dong et al., 2021 \\
\hline Apiaceae & Carrot & $\begin{array}{l}\text { Selenite or selenate, } \\
\leq 0.5 \mathrm{mM}\end{array}$ & Foliar spray & 1.5 or $2.2, \mathrm{DM}$ & $\begin{array}{l}\text { SeMet, } 0.43 \text { or } 0.37 \text {, } \\
\text { DM }\end{array}$ & Kápolna et al., 2009 \\
\hline Brassicaceae & $\begin{array}{l}\text { Broccoli, } \\
\text { cauliflower, green } \\
\text { cabbage, Chinese } \\
\text { cabbage, kale, and } \\
\text { Brussels sprouts }\end{array}$ & Selenate, $50 \mu \mathrm{M}$ & Hydroponic application & 160 on average, DM & $\begin{array}{l}\text { SeMeCys, } 80 \text { on } \\
\text { average, DM }\end{array}$ & Ávila et al., 2014 \\
\hline Brassicaceae & Broccoli & Selenate, $50 \mathrm{~g} \mathrm{ha}^{-1}$ & Foliar spray & 521-955, FM & $\begin{array}{l}\text { SeMet and SeMeCys, } \\
\text { 52-120, DM }\end{array}$ & $\begin{array}{l}\text { Šindelárová et al., } \\
2015\end{array}$ \\
\hline Brassicaceae & Broccoli & Selenate, $20 \mu \mathrm{M}$ & Hydroponic application & 801.2-1798.4, DM & $\begin{array}{l}\text { SeMet and SeMeCys, } \\
\text { about } 0.5 \mu \mathrm{Mg}^{-1} \mathrm{FM}\end{array}$ & Ramos et al., 2011 \\
\hline Brassicaceae & Cabbage & Selenate, $0.1 \mathrm{mM}$ or $2.6 \mu \mathrm{M}$ & $\begin{array}{l}\text { Foliar spray or soil } \\
\text { application }\end{array}$ & 0.96 or $4.80, \mathrm{DM}$ & $\begin{array}{l}\text { SeMet, } 0.18 \text { or } 2.52 \text {, } \\
\text { DM }\end{array}$ & Mechora et al., 2012 \\
\hline Brassicaceae & Pak choi & Selenite, $10 \mu \mathrm{M}$ & Hydroponic application & $2.22, \mathrm{FM}$ & SeMeCys, 0.61, FM & Yu et al., 2019 \\
\hline Brassicaceae & Pak choi & Selenate, $10 \mu \mathrm{M}$ & Hydroponic application & $42.17, \mathrm{FM}$ & SeMet, 6.46 FM & Yu et al., 2019 \\
\hline Brassicaceae & $\begin{array}{l}\text { Pak choi, kale, and } \\
\text { broccoli sprouts }\end{array}$ & Selenate, $<0.64 \mathrm{mM}$ & $\begin{array}{l}\text { Sand culture and } \\
\text { nutrient supplement }\end{array}$ & 155.9-467.1, DM & $\begin{array}{l}\text { SeMeCys, 57.4-168.9, } \\
\text { DM }\end{array}$ & $\begin{array}{l}\text { Thosaikham et al., } \\
2014\end{array}$ \\
\hline Brassicaceae & Radish & Nanoparticles, $12.7 \mu \mathrm{M}$ & Hydroponic application & $144, \mathrm{FM}$ & SeMeCys, 43, FM & $\begin{array}{l}\text { Palomo-Siguero et al., } \\
2015\end{array}$ \\
\hline Brassicaceae & Radish & Selenate, $\leq 10 \mu \mathrm{M}$ & Foliar spraying & 120, DM & SeMeCys, 33, DM & Schiavon et al., 2016 \\
\hline Brassicaceae & $\begin{array}{l}\text { White cabbage, } \\
\text { broccoli, mustard, } \\
\text { and rye sprouts }\end{array}$ & Selenium dioxide, $90.1 \mu \mathrm{M}$ & Hydroponic application & 53.3-400.0, DM & $\begin{array}{l}\text { SeMet and SeMeCys, } \\
\text { NG }\end{array}$ & Piekarska et al., 2014 \\
\hline Compositae & Lettuce & $\begin{array}{l}\text { Selenite or selenate, } \\
\leq 40 \mu \mathrm{M}\end{array}$ & Hydroponic application & 50.8 or $602.0, \mathrm{DM}$ & $\begin{array}{l}\text { SeMet, } 6.9 \text { or } 25.2 \text {, } \\
\text { DM }\end{array}$ & $\begin{array}{l}\text { do Nascimento da } \\
\text { Silva et al., } 2017\end{array}$ \\
\hline Leguminosae & Chickpea & $\begin{array}{l}\text { Selenite or selenate, } \\
\leq 40 \mathrm{gha}^{-1}\end{array}$ & Soil application & 0.70 or $2.92, \mathrm{DM}$ & $\begin{array}{l}\text { SeMet, } 0.46 \text { or } 1.52 \text {, } \\
\text { DM }\end{array}$ & $\begin{array}{l}\text { Poblaciones et al., } \\
2014\end{array}$ \\
\hline Leguminosae & $\begin{array}{l}\text { Lentil and soy } \\
\text { sprouts }\end{array}$ & $\begin{array}{l}\text { Selenite and selenate }(1: 1) \text {, } \\
\leq 23.1 \mu \mathrm{M}\end{array}$ & Hydroponic application & 98-284, DM & SeMet, 14.9-29.1, DM & $\begin{array}{l}\text { Funes-Collado et al., } \\
2013\end{array}$ \\
\hline Leguminosae & Soybean & Selenite, $5 \mu \mathrm{gg}^{-1}$ soil & Soil application & $75, \mathrm{DM}$ & SeMet and SeCys, NG & Chan et al., 2010 \\
\hline Liliaceae & Garlic & Nanoparticles, $12.7 \mu \mathrm{M}$ & Hydroponic application & About 22, DM & $\begin{array}{l}\text { SeMeCys, About } \\
\text { 16.06, DM }\end{array}$ & Li et al., 2020 \\
\hline Liliaceae & Garlic & $N G$ & $N G$ & 1.36, DM & SeMeCys, NG & Kotrebai et al., 2000 \\
\hline Liliaceae & Onion & $N G$ & $N G$ & $0.14, \mathrm{DM}$ & SeMeCys, NG & Kotrebai et al., 2000 \\
\hline Liliaceae & Ramp & $N G$ & $N G$ & $0.52, \mathrm{DM}$ & SeMeCys, NG & Kotrebai et al., 2000 \\
\hline Solanaceae & Potato & $\begin{array}{l}\text { Selenite or selenate, } \\
100 \mathrm{gha}^{-1}\end{array}$ & Foliar spray & 0.78 or $1.22, \mathrm{DM}$ & $\begin{array}{l}\text { SeMet, } 0.61 \text { or } 0.41 \text {, } \\
\text { DM }\end{array}$ & Zhang et al., 2019b \\
\hline Solanaceae & Potato & Selenate, $52.7 \mu \mathrm{M}$ & Foliar spray & 1.1, DM & SeMet, 0.33, DM & Cuderman et al., 2008 \\
\hline
\end{tabular}

DM, dry matter; FM, fresh matter; and NG, not given.

while other vegetables tend to accumulate SeMet. For vegetables that mainly accumulate MeSeCys, the highest total Se concentration was found in broccoli $\left(1798.4 \pm 58.8 \mu \mathrm{gg}^{-1} \mathrm{DM}\right)$ and the highest MeSeCys concentration was found in broccoli sprout $\left(168.9 \pm 19.0 \mu \mathrm{gg}^{-1} \mathrm{DM}\right)$. For those mainly accumulate SeMet, the highest total Se concentration was found in lettuce $\left(602.0 \pm 6.0 \mu \mathrm{gg}^{-1} \mathrm{DM}\right)$ and the highest SeMet concentration was found in Lion's Mane mushroom $\left(55.1 \pm 11.1 \mu \mathrm{gg}^{-1} \mathrm{DM}\right)$. Studies reported that MeSeCys can be quickly converted into methyl selenol, which exerts putative anti-cancer activity
(Ip et al., 2000). Therefore, vegetables from the Brassicaceae and Liliaceae families may represent suitable dietary sources for Se supplementation.

\section{Percentage of Minimum Recommended Daily Allowance and Acceptable Daily Intake Based on Se Accumulation}

Dietary intake of Se is largely dependent on the soil levels of Se, which vary in different regions. Daily Se intake is less than $11 \mu \mathrm{g}$ in the Se-deficient regions of China where Keshan and 
Kashin-Beck diseases occur (Liu et al., 2018); in contrast, the average Se intake is $550 \mu \mathrm{g}$ per day in Enshi, China, a Se-rich region (Yuan et al., 2012; Huang et al., 2013). However, it was suggested that an intake of above $400 \mu \mathrm{g}$ Se per day would lead to chronic toxicity (Winkel et al., 2012; Malagoli et al., 2015). Due to the narrow safe intake range, daily consumption of Se-enriched vegetables should be carefully considered. Therefore, based on the current biofortification methods (Table 1), we calculated the percentage of minimum recommended daily allowance and acceptable daily intake for Se-enriched vegetables and mushrooms (Table 2). The water contents of vegetables used in these calculations were taken from Food Data Central Database (United States Department of Agriculture Food Data Central Database, 2021). We found that $100 \mathrm{~g}$ of cabbage, carrot, chickpea, onion, or potato provide less Se than the minimum recommended daily allowance. The same quantities of other vegetables meet the minimum recommended daily allowance, and most exceed the acceptable daily intake. Therefore, it is important to control the Se content of vegetables within a suitable range and to increase the proportion of Se-AAs in vegetables.

\section{FACTORS THAT AFFECT Se SPECIATION}

Several authors reviewed factors that affect bioavailability of Se (the fraction of Se that is available for absorption by plant) in soil-plant system, including Se speciation, soil property $(\mathrm{pH} /$ Eh, metallic oxide, and organic matter and clay contents), plant condition (species, cultivar, and growth stage), climate condition, and agronomic management (tillage management, irrigation, rotation and intercrop management, and fertilizer). Such factors also have impacts on the Se speciation in plants. We summarized the related studies and discussed factors that affect Se speciation, including Se source, agronomic management, and vegetable species and cultivars.

TABLE 2 | Calculated percentage of minimum recommended daily allowance and acceptable daily intake for selenium-enriched vegetables and mushrooms.

\begin{tabular}{|c|c|c|c|}
\hline Vegetable & $\begin{array}{l}\text { Se content ( } \mu \mathrm{g} \\
\left.100 \mathrm{~g}^{-1} \mathrm{FM}\right)\end{array}$ & $\begin{array}{c}\text { Percentage of } \\
\text { MRDA (\%) }\end{array}$ & $\begin{array}{c}\text { Percentage of } \\
\text { ADI (\%) }\end{array}$ \\
\hline Brassica sprouts & $2026.7-6072.3$ & 3684.9-11040.5 & $506.7-1518.1$ \\
\hline Broccoli & $8012.0-95,500$ & $14567.3-173636.4$ & 2003.0-4496.0 \\
\hline Cabbage & 6.7-33.6 & 12.2-61.1 & $1.7-8.4$ \\
\hline Carrot & $14.9-21.8$ & 27.0-39.6 & $3.7-5.4$ \\
\hline Chickpea & $2.8-11.7$ & $5.1-21.2$ & $0.7-2.9$ \\
\hline Garlic & $50.2-811.8$ & $91.2-1476.0$ & 12.5-203.0 \\
\hline Lettuce & 269.2-3190.6 & 489.5-5801.1 & 67.3-797.7 \\
\hline $\begin{array}{l}\text { Lentil and soy } \\
\text { sprouts }\end{array}$ & 3038.0-8804.0 & $5523.6-16007.3$ & 759.5-2201.0 \\
\hline Mushroom & $33.6-1118.0$ & $61.1-2032.7$ & $8.4-279.5$ \\
\hline Onion & 1.4 & 2.5 & 0.4 \\
\hline Pak choi & 222.0-4217.0 & 403.6-7667.3 & 55.5-1054.3 \\
\hline Potato & 17.2-26.8 & $31.2-48.8$ & 4.3-6.7 \\
\hline Radish & 480.0-14400.0 & $872.7-26181.8$ & 120.0-3600.0 \\
\hline Soybean & 405.0 & 736.4 & 101.3 \\
\hline
\end{tabular}

MRDA, minimum recommended daily allowance and ADI, acceptable daily intake.

\section{Se Source}

Selenite, selenate, Se nanoparticles, and Se-AAs can be absorbed by vegetables (Dinh et al., 2019). They are assimilated into various Se metabolites in the cells of vegetables (Figure 2). Vegetables, such as turnip (Li et al., 2018a), lettuce (HawrylakNowak, 2013), and green pea (Garousi et al., 2017), accumulate more Se contents by supplying selenate as compared with selenite. Studies also showed that selenate treatment resulted in more Se-AA contents in pak choi (Yu et al., 2019) and potato (Zhang et al., 2019b). Selenite and selenate are transported by phosphate transporters and sulfate transporters, respectively (Feist and Parker, 2001; Li et al., 2008; El Mehdawi et al., 2018), and compete with one another when they coexist. Selenite-inhibited selenate uptake and transport in wheat (Li et al., 2008), whereas high concentrations $(0.63 \mu \mathrm{M})$ of selenate prevented selenite absorption in maize (Longchamp et al., 2013). The Se nanoparticles were found to be transported by aquaporins (Hu et al., 2018; Wang et al., 2020a), and their metabolic fate was similar to that of selenite (Palomo-Siguero et al., 2015; Hu et al., 2018; Wang et al., 2020a). It was suggested that Se-AAs may be transported by amino acid transporters (Kikkert and Berkelaar, 2013). However, vegetables contain dozens of amino acid transporters (Yang et al., 2020), and the specific amino acid transporters that transport Se-AAs have not yet been identified.

\section{Inorganic Se as a Se Source for Biofortification}

Selenite and selenate are frequently employed as inorganic sources of Se for plant biofortification. Absorbed selenite is rapidly converted into Se-AAs in the roots of wheat ( $\mathrm{Li}$ et al., 2008) and pak choi (Yu et al., 2019), with only a small proportion of selenite being translocated to the shoots. In contrast, selenate is gradually converted into Se-AAs in the roots, with the majority of selenate being translocated to the shoots.

The Se nanoparticles have recently been proposed as a new type of fertilizer and can be synthesized via physical, chemical, or biological processes (Wadhwani et al., 2016; Skalickova et al., 2017) with varied particle sizes, stabilities, and bioavailabilities. Several studies have revealed that Se nanoparticles are oxidized to selenite in plants, implying that their metabolic fate is similar to that of selenite (Palomo-Siguero et al., 2015; Hu et al., 2018; Wang et al., 2020a). However, different plants exhibit distinct patterns of biotransformation of Se nanoparticles. Rice seedlings more efficiently biotransformed Se nanoparticles into Se-AAs than wheat seedlings which were grown in nutrient solutions in greenhouses (Hu et al., 2018; Wang et al., 2020a).

Even though inorganic sources of Se are largely used for vegetable biofortification, they have two disadvantages. Firstly, inorganic Se can only be used in low concentrations, otherwise stunting of root and plant growth, chlorosis, or withering may occur (Terry et al., 2000). Secondly, only some of the inorganic Se is biotransformed into Se-AAs. High proportions of the inorganic forms remain in vegetables (Thosaikham et al., 2014). Therefore, alternative strategies need to be explored to improve the bioavailability of inorganic Se to vegetables and to reduce the proportion of inorganic $\mathrm{Se}$ in the edible parts of vegetables. 


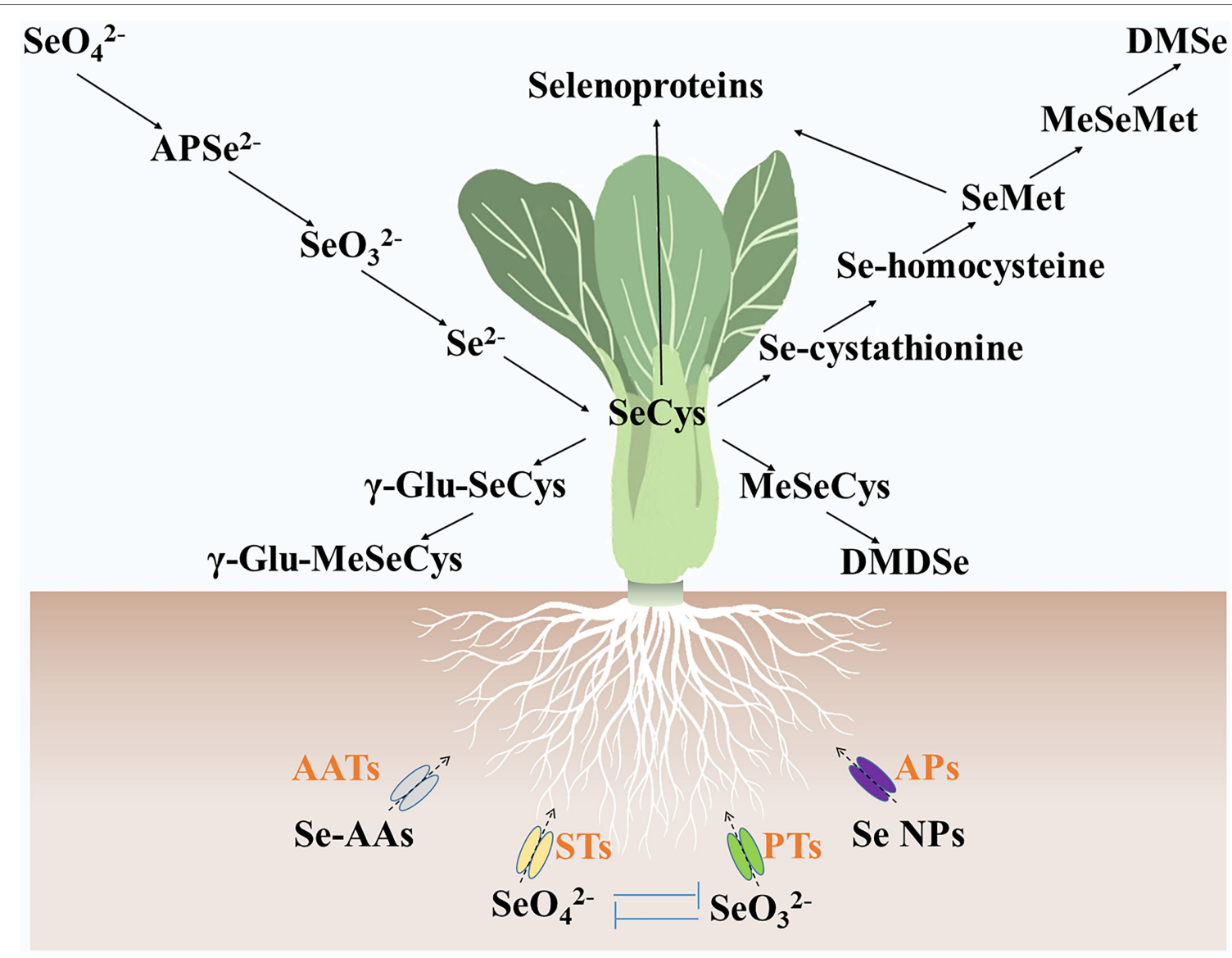

FIGURE 2 | Metabolic fate of selenium in vegetables. Se-AAs, selenate, selenite, and Se nanoparticles are absorbed by vegetables via amino acid transporters, sulfate transporters, phosphate transporters, and aquaporins, respectively. Then, these selenium forms were assimilated into various selenium metabolites, such as adenosine phosphoselenate, SeCys, $\gamma$-glutamyl-selenocysteine, $\gamma$-Glu-MeSeCys, MeSeCys, Se-cystathionine, Se-homocysteine, SeMet, Semethylselenomethionine, dimethyldiselenide, dimethylselenide, and selenoproteins. AATs, amino acid transporters; APs, aquaporins; PTs, phosphate transporters; and STs, sulfate transporters. $\mathrm{SeO}_{3}{ }^{2-}$, Selenite; APSe ${ }^{2-}$, adenosine phosphoselenate; $\mathrm{SeO}_{4}{ }^{2-}$, selenate; Se NPs, Se nanoparticles; $\gamma$-Glu-SeCys, $\gamma$-glutamylselenocysteine; MeSeMet, Se-methylselenomethionine; DMDSe, dimethyldiselenide; and DMSe, dimethylselenide.

\section{Organic Se as a Se Source for Biofortification}

Organic Se is the main form in agricultural soils under different cropping systems in Enshi, China, which accounts for 56-81\% of the total Se (Qin et al., 2017). They have distinct availabilities to different plants. Kikkert and Berkelaar (2013) determined that SeMet and SeCys were more readily absorbed by durum wheat and spring canola than inorganic Se. It was also shown that SeMet was more effective than selenate for the production of Se-enriched garlic and Indian mustard (Ogra et al., 2017). On the contrary, inorganic Se was more bioavailable to oilseed rape than Se-AAs (Ebrahimi et al., 2015). In addition, EichGreatorex et al. (2007) found no differences in the uptake of organic Se (Se yeast and SeMet) and inorganic Se (selenate) fertilizers in wheat, barley, and oats. These results imply that Se-AAs can be utilized by plants; however, there is limited detailed information on the absorption, translocation, and accumulation of Se-AAs in individual vegetables.

We hypothesize that Se-AAs, particularly water-soluble MeSeCys and methylselenomethionine, can be absorbed directly by plants as several families of amino acids transporters have been identified, including the amino acid transporter family, amino acid-polyaminecholine, mitochondrial carrier family, preprotein and amino acid transporters, and the divalent anion: $\mathrm{Na}^{+}$symporter (Rentsch et al., 2007). In addition, methionine was previously reported to hinder SeMet uptake (Sandholm et al., 1973), implying that SeMet and methionine share the same transporters. Frommer et al. (1993) identified a broad specificity amino acid permease (pAAP1) in Arabidopsis thaliana that transported proline via a process in which methionine was a strong competitor. Therefore, pAAP1 may be capable of transporting SeMet.

The Se hyperaccumulators, such as Astragalus and Stanleya pinnata species, are not edible, at least not directly. These plants are rich in MeSeCys or SeMet and hence could be employed as organic Se sources for vegetable biofortification (Bañuelos et al., 2015, 2016; Wu et al., 2015). The use of seed meals derived from Se-enriched mustard and canola was shown to increase the Se content of strawberry fruits (Banuelos and Hanson, 2010). Amendment of the soil with Se-enriched Stanleya pinnata led to production of carrots and broccoli with SeMet as the predominant organic Se compound (Bañuelos et al., 2015, 2016). 
Wang et al. (2018) revealed that amendment of Se-enriched wheat straw and pak choi increased the soil respiration rate and resulted in increased levels of soluble Se, exchangeable Se, and fulvic acid-bound Se, all of which contributed to higher Se bioavailability. Importantly, Se-enriched plants should be pre-incubated in soils to ensure the bioavailability of Se (Stavridou et al., 2011); otherwise, a reduced efficiency of Se uptake and fertilizer recovery would be observed (Ebrahimi et al., 2019). Overall, the Se present in Se-enriched plants is accessible to plants, and thus, Se hyperaccumulators, such as Astragalus species, that grow in Se-rich areas have the potential to be employed as natural and green sources of Se; a better understanding of the metabolic fate of MeSeCys and SeMet would help to rationally develop Se resources and produce Se-enriched vegetables with high-Se-AA contents.

\section{Agronomic Management}

Agronomic management has been widely used to regulate the quality of vegetables (Yang et al., 2021). Current studies indicate that the method and timing of application of Se fertilizers, mineral elements in the rhizosphere, and external conditions affect the levels of Se-AAs in various plant species, though only a few studies have investigated these factors in vegetables. However, these results may provide practical guidance for production of Se-enriched vegetables with high-Se-AA contents.

\section{Application Method and Timing of Se Fertilizers}

The Se fertilizers are generally applied via foliar and root application. Foliar application offers the advantages of enhanced utilization efficiency associated with prevention of environmental pollution (Niu et al., 2021). Application of Se at a critical growth stage is essential to ensure higher plant Se-AA contents. Studies have shown that the levels of organic Se were 2-fold higher in rice grains sprayed with $75 \mathrm{gha}^{-1}$ of selenate or selenite at the full heading stage than plants treated at the late tillering stage (Deng et al., 2017). In wheat, foliar spraying of $20 \mathrm{gha}^{-1}$ selenate at the pre-filing stage increased organic Se (mainly SeMet) by $5.34 \%$ compared to spraying at the pre-flowering stage (Wang et al., 2020b). In blueberry plants, foliar application of $200 \mathrm{~g} \mathrm{ha}^{-1}$ selenate or selenite during the young fruiting stage resulted in 12.9-16.6\% higher organic Se levels than treatment during the coloring stage (Li et al., 2018b).

Even though foliar application has advantages, Yin et al. (2019) found that root application of Se led to 91.2-97.1\% higher Se-AA levels in rice than foliar application. However, root application generally adds more Se fertilizer to the soil and water, which leads to concerns related to possible long-term environmental impacts (Tan et al., 2016). Therefore, it is critical to optimize the application methods for different vegetables.

\section{Mineral Elements in the Rhizosphere}

Duncan et al. (2017) found that nitrogen fertilizers increased the total Se content and the proportion of undefined Se by $60-70 \%$ but decreased the major form of organic Se (SeMet) in wheat grains. Additionally, phosphorus and sulfur have been established to compete for selenite and selenate absorption, respectively (Feist and Parker, 2001; Li et al., 2008; El Mehdawi et al., 2018). Interestingly, phosphorus application at $160 \mu^{g^{-1}}$ decreased the total and organic Se contents in the grains of winter wheat, while the proportion of organic Se increased by $7.2-15.1 \%$ compared to no phosphorus application (Nie et al., 2020). Although sulfur deficiency enhanced the total Se content of wheat seedlings supplied with $10 \mu \mathrm{M}$ selenate, the contents of MeSeCys in the shoots and roots decreased by 74.9 and $82.3 \%$, respectively (Huang et al., 2017).

\section{External Condition}

External conditions, such as climate conditions and soil properties, have influences on the bioavailability of Se through affecting the absorption of Se by vegetables and Se fraction and speciation in the soil (Dinh et al., 2019). Renkema et al. (2012) found that enhanced transpiration at around $50 \%$ relative humidity increased Se translocation by up to 6-fold in durum wheat and spring canola. Soil $\mathrm{pH}$ governs Se speciation and changes the charges of bioavailable Se (Nakamaru and Altansuvd, 2014; Ponton et al., 2018). SeMet becomes negatively charged as the $\mathrm{pH}$ increases from 7 to 10; therefore, SeMet is more bioavailable at high $\mathrm{pH}$ (Ponton et al., 2018). Numerous studies have also been conducted to determine the influence of selenobacteria (Se biofortification by certain bacteria in the soil) on the accumulation of $\mathrm{Se}$ in plants. Several genera, including Acinetobacter, Bacillus, Enterobacter, Klebsiella, Paenibacillus, Pseudomonas, and Stenotrophomonas, were isolated and identified as Se-tolerant (Acuña et al., 2013; Durán et al., 2014). Among them, Acinetobacter E6.2 produced elevated levels of SeMet $\left(10.0 \mu \mathrm{gg}^{-1} \mathrm{DM}\right)$ and MeSeCys $\left(3.8 \mu \mathrm{gg}^{-1} \mathrm{DM}\right)$ without causing oxidative stress (Durán et al., 2015). In addition, co-inoculation of selenobacteria with an arbuscular mycorrhizal fungus further enhanced Se accumulation (Durán et al., 2013, 2016). However, organic matter existed in the soil or organic amendments reduced Se bioavailability to plants by immobilizing Se (Li et al., 2017).

Overall, agronomic management represents a practical method of obtaining Se-enriched vegetables with high-Se-AA contents. Thus, it is important to investigate the optimal application methods and timing of Se fertilization for specific vegetable crops. Phosphorus and sulfur are essential to obtain high contents of Se-AAs, while nitrogen and organic matter should be carefully controlled. Moreover, even though high $\mathrm{pH}$, enhanced transpiration, and selenobacteria have been shown to be beneficial for Se accumulation, the Se speciation and their contents were not determined in the previous studies. Future studies should focus on the precise effects of external conditions on the Se-AAs accumulated by vegetable crops.

\section{Vegetable Species and Cultivars}

Uptake and accumulation of Se are distinct in different plant species. The Se hyperaccumulators generally accumulate 10- to 100 -fold higher levels of Se than Se non-accumulators. These plants exhibit higher Se to sulfur ratios (Se preference), organic Se to inorganic Se ratios, shoot to root Se ratios, and source to sink Se ratios (Pilon-Smits, 2017). By taking advantage of elevated selenocysteine methyltransferase (SMT) levels, Se hyperaccumulators produce methylated forms of SeMet and SeCys, 
rather than integrating these Se-AAs into proteins (Pilon-Smits, 2017). The Se hyperaccumulators are also capable of converting SeCys to elemental Se and alanine (Guignardi and Schiavon, 2017). In addition, they have higher contents of hormones (jasmonic acid, salicylic acid, and ethylene) and enhanced levels of stress-resistance genes, which contribute to Se assimilation and tolerance (Pilon-Smits, 2017). As a result, Se is less hazardous to Se hyperaccumulators, and Se hyperaccumulators generally have higher total Se and Se-AA contents than other plants (Finley, 2005; Wiesner-Reinhold et al., 2017). Similar to Se hyperaccumulators, vegetables from the Brassicaceae and Liliaceae families accumulate more total Se and higher MeSeCys contents (Table 1). Moreover, vegetables from the Brassicaceae family are tolerant to high concentrations of inorganic Se $(0.64 \mathrm{mM}$ of selenate by nutrient supplementation, Table 1).

Cultivar also has influence on uptake and accumulation of Se. It was reported that high-Se rice cultivars have been shown to alter the mass flow and activate Se by increasing the rhizospheric $\mathrm{pH}$ and secreting organic acids into rhizosphere, which result in improved Se bioavailability (Zhang et al., 2019c). In addition, total contents of SeCys, MeSeCys, and SeMet in broccoli heads were cultivar dependent, ranging from 0.20 to $0.66 \mu \mathrm{gg}^{-1} \mathrm{DM}$ (Šindelářová et al., 2015).

\section{METABOLISM OF Se-AAs}

\section{Regulation of Se-AAs in Vegetables}

Several molecular studies have been conducted to reveal the mechanisms of detoxification in Se hyperaccumulators. The Se hyperaccumulators have been found to mitigate Se toxicity by converting SeCys to methylated and/or volatile forms (Figure 3A), decomposing SeCys (Figure 3B), and preventing SeCys misincorporation (Figure 3C). These findings provide important information for molecular breeding of Se-enriched vegetables with high-Se-AA contents.

The Se hyperaccumulators may exhibit increased expression of Se-assimilation genes (Lima et al., 2018). They also predominantly contain water-soluble and non-protein forms of organic Se compounds, such as MeSeCys (Pilon-Smits, 2017). Researchers have identified SMT genes that specifically methylate selenocysteine and homocysteine in vegetables, such as broccoli (Lyi et al., 2005) and Indian mustard (Chen et al., 2019). Overexpression of SMT increased the levels of MeSeCys by more than $95.6 \%$ (with selenite as the Se source) or $72.4 \%$ (with selenate as the Se source) in tomato fruits (Brummell et al., 2011). Apart from the expression levels of SMT, the enzyme activity of SMT is also important. Sors et al. (2009) reported that the SMT of a non-accumulator Astragalus drummondii lacked activity in vitro, while insertion of mutations increased its activity. The WRKY47 gene and cytokinin have been associated with Se tolerance in Arabidopsis thaliana. The wrky47 mutants of A. thaliana are sensitive to Se stress; these mutants exhibit decreased expression of $H M T 1$ and $H M T 3$, which share significant primary sequence homology with SMT (Wu et al., 2020). The tps22 mutants have decreased exogenous levels of cytokinins, which resulted in increased SMT expression (Jiang et al., 2018). Moreover, overexpression of the genes encoding cystathionine- $\gamma$ synthase (CGS) and COQ5 methyltransferase (COQ5-2) increased the production of volatile Se compounds, resulting in a lower Se content and decreased toxicity, in Indian mustard and broccoli, respectively (Huysen et al., 2003, 2004; Zhou et al., 2009).

Decomposing SeCys avoids misincorporation of SeCys into proteins. Overexpression of the genes encoding NifS-like protein (CPNifS) and selenocysteine lyase ( $c p S L)$ enhanced conversion of SeCys into alanine and elemental Se in A. thaliana and Indian mustard, respectively (Van Hoewyk et al., 2005; Bañuelos et al., 2007). Decreasing misincorporation of SeCys may reduce toxicity and increase the content of Se-AAs. A variant cysteinyltRNA synthetase $(C y s R S)$ that reduced the frequency of SeCys misincorporation was identified in Se hyperaccumulator Astragalus bisulcatus (Hoffman et al., 2019).

In the absence of the abilities described above, Se non-accumulators are sensitive to Se supplementation, thus absorb and accumulate less total Se, and have lower Se-AA contents. Therefore, further studies are needed to select and

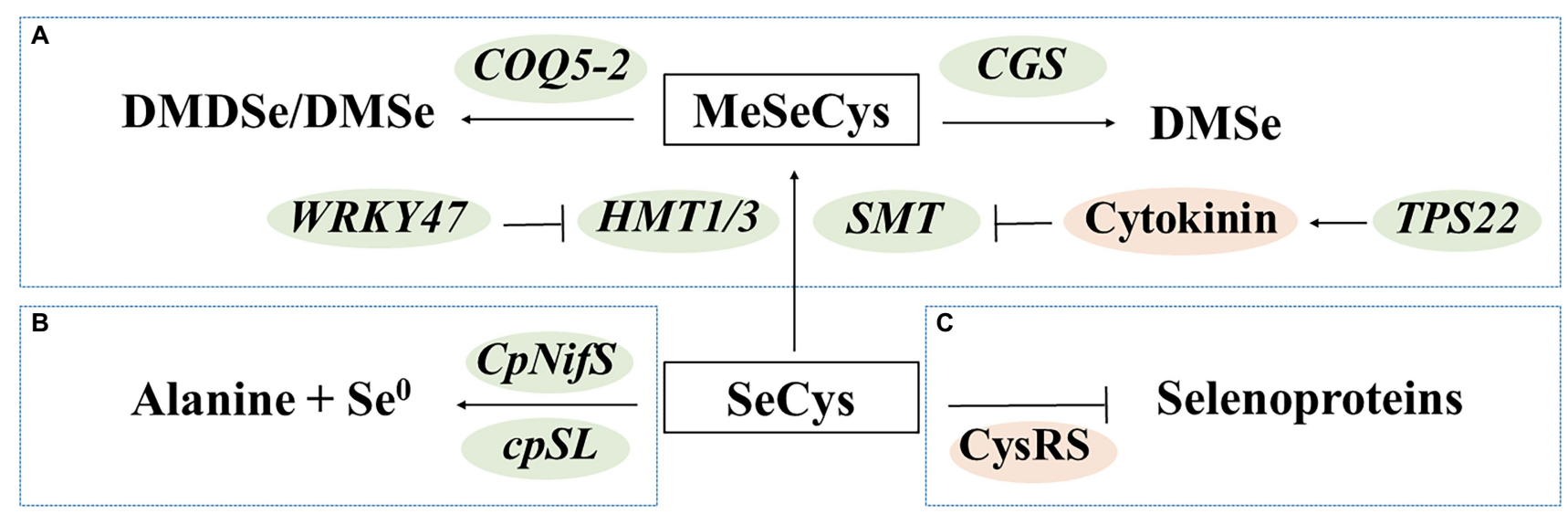

FIGURE 3 | Transgenic approaches to regulate seleno-amino acids in plants. (A) Production of methylated and/or volatile forms; (B) Decomposition of SeCys; and (C) Reduction of misincorporation. DMDSe, dimethyl diselenide; DMSe, dimethyl selenide; MeSeCys, Se-methylselenocysteine; and SeCys, selenocysteine. 
breed vegetable cultivars with Se hyperaccumulator abilities. In addition, other genes involved in the transport and assimilation of inorganic Se have the potential to increase the content of Se-AAs. Researchers found that sulfate transporters (Sultr) and ATP sulphurylases (APS) play important roles in the accumulation of Se (Schiavon et al., 2015) and that overexpression of the phosphate transport gene (OsPT8) improved the Se content of Nicotiana tabacum (Song et al., 2017). However, it is a pity that the Se-AA contents were not determined in these studies.

\section{Future Research Prospects}

As described above, Se-AAs can be used as effective, green sources for Se biofortification. However, it is unknown whether Se-AAs are mineralized or directly absorbed by plants, what happens when Se-AAs are allocated into the roots and shoots, and how plants transport Se-AAs from their roots to the shoots (Figure 4A).

Researchers have generally addressed these issues by applying multiple analytical techniques (Figure 4B); however, these analytical techniques have some limitations. Isotope labeling has been used to investigate the metabolic fate and translocation of substances for many years, though the applicability of this approach is limited by the scarcity of isotopically labeled Se speciation (Pedrero and Madrid, 2009; Abdillah et al., 2021). The Se speciation is generally identified by coupling multiple techniques, such as high-performance liquid chromatography in conjunction with inductively coupled plasma mass spectrometry (HPLC-ICP-MS). Fluorescent probes have also been developed for the detection of Se-AAs (Abdillah et al., 2021). However, many probes perform poorly under the physiological conditions of living cells. Therefore, Guo et al. (2020b) designed an $\mathrm{Au}$ nanoparticle-based probe for detecting SeCys in plants, such as rice and tea.

The transporters of Se-AAs could be identified using highthroughput sequencing. Plant factories with artificial lighting (PFAL) system provide stable environmental conditions and can be used year-round to grow plants. Amino acid permeases that are responsible for the uptake and transport of Se-AAs could potentially be identified through precise management of environmental conditions and a variety of traits using PFALs. Overall, combined use of multiple technologies would be preferable for determining the mechanisms of uptake and translocation of Se-AAs in vegetables.

\section{PERSPECTIVES}

Improving the Se-AA contents of vegetables benefits human health and increases the economic value of vegetables. This review summarized previous research on the forms and metabolism of Se-AAs in vegetables. To produce safe and effective Se-enriched vegetables, a number of important issues still need to be elucidated, such as (1) how can we improve the accumulation of Se-AAs in vegetables and (2) how can we control the ratios of total Se and Se-AA contents of vegetables. Hereafter, we discuss these issues in detail and propose possible solutions.

\section{Cultivar Selection as an Important Strategy to Improve Accumulation of Se-AAs}

Biosynthesis of Se-AAs varies between different cultivars, including wheat (Duncan et al., 2017; Wang et al., 2021), potato (Cuderman et al., 2008), and pear (Bañuelos et al., 2012). It was reported that two rice cultivars supplied with SeMet accumulated significantly different Se contents (Zhang et al., 2006); the high-Se rice cultivar expresses more transporter genes and has a more optimal grain storage capacity than the low-Se rice cultivar (Zhang et al., 2020). In addition, accumulation of Se-AAs can be improved by enhancing their translocation. Amino acid permeases may function as
A
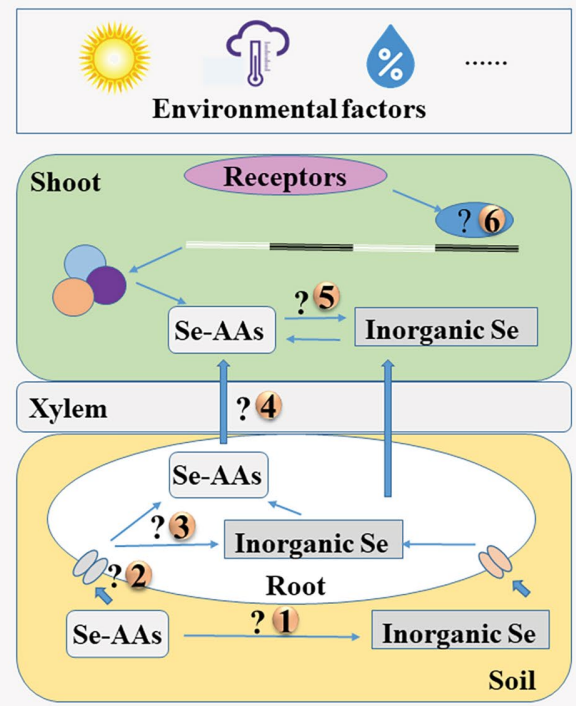

B

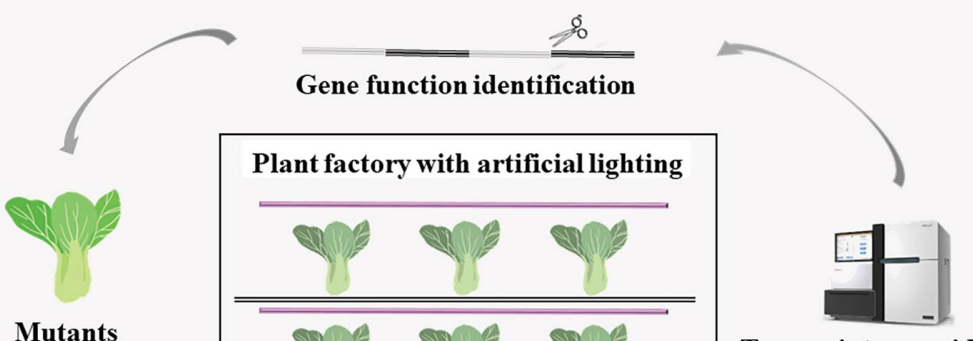

Transcriptome-wide and Genome-wide comparison
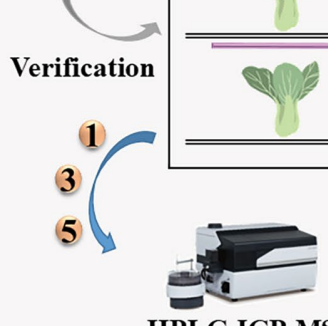

HPLC-ICP-MS Isotope labelling Fluorescence probe

FIGURE 4 | (A) Key issues in research of seleno-amino acids in vegetables and (B) the proposed strategies to address these issues. HPLC-ICP-MS, highperformance liquid chromatography in conjunction with inductively coupled plasma mass spectrometry; Se-AAs, seleno-amino acids; and Se, selenium. 
transporters of Se-AAs, as they transport amino acids from the soil into root cells and allocate the Se-AAs from the roots to shoots (Garneau et al., 2018; Guo et al., 2020a). As mentioned above, the majority of Se-AAs accumulated in the roots of wheat and pak choi. The Se-AAs did not appear to translocate to the shoots, which could be due to a lack of or low expression of amino acid permeases. These findings suggest that certain cultivars have a high capacity for Se-AA biosynthesis, translocation, and accumulation.

We propose that cultivar selection is an important strategy to obtain vegetable cultivars with a high capacity for Se-AA biosynthesis, translocation, and accumulation. However, conventional breeding strategies generally take a relatively long time. The PFALs could be considered as an ideal instrument to accelerate the breeding system. The PFALs allow the plant phenological period to be shortened by controlling important key factors, such as the lighting conditions, temperature, and nutrients supplied, to accelerate plant growth and development and to achieve the mature stage in a relatively short period.
Indeed, five generations of short-day crops can be produced per year using PFALs (Jähne et al., 2020).

\section{Regulation of Total Se and Se-AAs in Vegetables by PFAL and Artificial Intelligence}

The PFALs equipped with intelligent decision support systems have the potential to be a valuable instrument for producing vegetables with the desired Se contents and high proportions of Se-AAs. Machine learning algorithms based on artificial intelligence have been widely used in agriculture, for applications, such as the prediction of gene function (Mahood et al., 2020), crop yield (Yoosefzadeh-Najafabadi et al., 2021), and heavy metal contents (Shi et al., 2016). However, there are no examples of machine learning to study the regulation of health-promoting components in vegetables.

Here, we propose a Precise Control of Se Content (PCSC) production system to regulate the total Se and Se-AA contents of vegetables (Figure 5). To initiate this system, the researchers

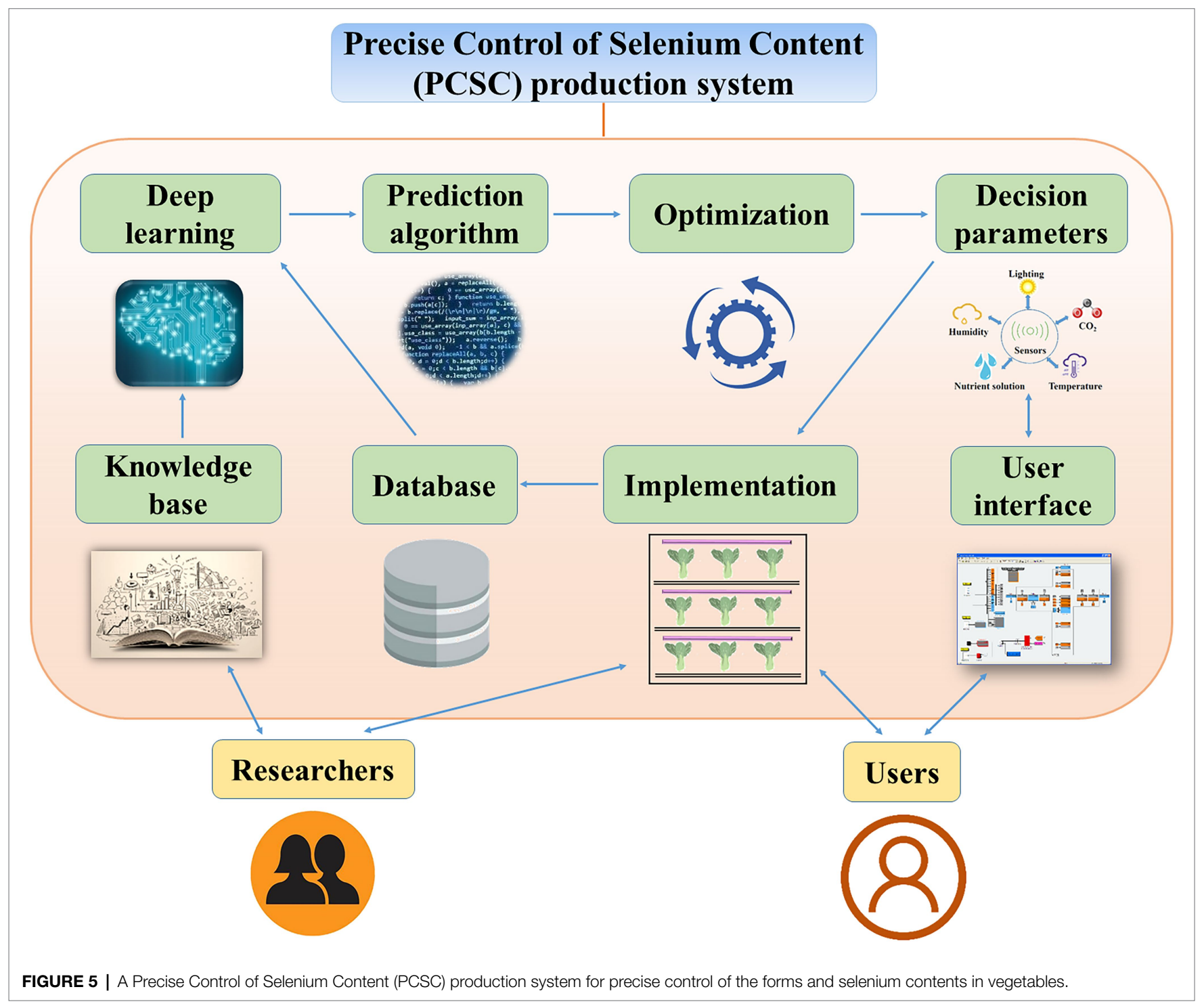


would define the treatments based on the desired Se content for the vegetables. Experimental data on the forms of Se, lighting conditions, humidity, temperature, and cultivar would be collected to establish a knowledge base. Next, the knowledge base would be utilized in machine deep learning. The decision parameters could be obtained by selecting an appropriate prediction algorithm according to the users' objectives. However, to make more accurate decisions, an optimization model needs to be constructed. Then, the decision parameters would be tested in the PFAL. The results of the implementation would be collected in the database and would be subjected to further deep learning and prediction algorithm processes. After accumulation of vast data and repeated optimizations, the results would become increasingly accurate and therefore enable precise control of the total Se and Se-AA contents of vegetables. Although Se source, environmental condition, and plant species are known to affect the accumulation and regulation of the total Se and Se-AA contents of vegetables, detailed data and the precise mechanics remain vague.

\section{REFERENCES}

Abdillah, A., Sonawane, P. M., Kim, D., Mametov, D., Shimodaira, S., Park, Y., et al. (2021). Discussions of fluorescence in selenium chemistry: recently reported probes, particles, and a clearer biological knowledge. Molecules 26:692. doi: 10.3390/molecules26030692

Acuña, J. J., Jorquera, M. A., Barra, P. J., Crowley, D. E., and de la Luz Mora, M. (2013). Selenobacteria selected from the rhizosphere as a potential tool for Se biofortification of wheat crops. Biol. Fertil. Soils 49, 175-185. doi: 10.1007/s00374-012-0705-2

Ávila, F. W., Yang, Y., Faquin, V., Ramos, S. J., Guilherme, L. R. G., Thannhauser, T. W., et al. (2014). Impact of selenium supply on Semethylselenocysteine and glucosinolate accumulation in selenium-biofortified Brassica sprouts. Food Chem. 165, 578-586. doi: 10.1016/j. foodchem.2014.05.134

Bañuelos, G. S., Arroyo, I. S., Dangi, S. R., and Zambrano, M. C. (2016). Continued selenium biofortification of carrots and broccoli grown in soils once amended with Se-enriched S. pinnata. Front. Plant Sci. 7:1251. doi: 10.3389/fpls.2016.01251

Bañuelos, G. S., Arroyo, I., Pickering, I. J., Yang, S. I., and Freeman, J. L. (2015). Selenium biofortification of broccoli and carrots grown in soil amended with Se-enriched hyperaccumulator Stanleya pinnata. Food Chem. 166, 603-608. doi: 10.1016/j.foodchem.2014.06.071

Banuelos, G. S., and Hanson, B. D. (2010). Use of selenium-enriched mustard and canola seed meals as potential bioherbicides and green fertilizer in strawberry production. HortScience 45, 1567-1572. doi: 10.21273/ HORTSCI.45.10.1567

Bañuelos, G. S., Leduc, D. L., Pilon-Smits, E. A., and Terry, N. (2007). Transgenic Indian mustard overexpressing selenocysteine lyase or selenocysteine methyltransferase exhibit enhanced potential for selenium phytoremediation under field conditions. Environ. Sci. Technol. 41, 599-605. doi: 10.1021/es061152i

Bañuelos, G. S., Stushnoff, C., Walse, S. S., Zuber, T., Yang, S. I., Pickering, I. J., et al. (2012). Biofortified, selenium enriched, fruit and cladode from three Opuntia Cactus pear cultivars grown on agricultural drainage sediment for use in nutraceutical foods. Food Chem. 135, 9-16. doi: 10.1016/j. foodchem.2012.04.021

Bhatia, P., Aureli, F., D’Amato, M., Prakash, R., Cameotra, S. S., Nagaraja, T. P., et al. (2013). Selenium bioaccessibility and speciation in biofortified Pleurotus mushrooms grown on selenium-rich agricultural residues. Food Chem. 140, 225-230. doi: 10.1016/j.foodchem.2013.02.054

Brummell, D. A., Watson, L. M., Pathirana, R., Joyce, N. I., West, P. J., Hunter, D. A., et al. (2011). Biofortification of tomato (Solanum lycopersicum) fruit with the anticancer compound methylselenocysteine using a selenocysteine
Therefore, further investigations are required to establish the proposed PCSC production system.

\section{AUTHOR CONTRIBUTIONS}

$\mathrm{JH}$ and $\mathrm{XY}$ created the hypothesis, objectives, outline the draft, and wrote the manuscript. ZW, LZ, JP, TH, BJ, and QY edited and added the discipline-specific feedback. All authors contributed to the article and approved the submitted version.

\section{FUNDING}

This work was financially supported by the National Key Research and Development Program of China (no. 2020YFE0203600), Central Public-Interest Scientific Institution Basal Research Fund (no. Y2021XK04), and the Agricultural Science and Technology Innovation Program (34-IUA-01 and 34-IUA-03).

methyltransferase from a selenium hyperaccumulator. J. Agric. Food Chem. 59, 10987-10994. doi: 10.1021/jf202583f

Burk, R. F., and Hill, K. E. (2015). Regulation of selenium metabolism and transport. Annu. Rev. Nutr. 35, 109-134. doi: 10.1146/annurevnutr-071714-034250

Chan, Q., Afton, S. E., and Caruso, J. A. (2010). Selenium speciation profiles in selenite-enriched soybean (Glycine Max) by HPLC-ICPMS and ESI-ITMS Metallomics 2, 147-153. doi: 10.1039/B916194E

Chen, M., Zeng, L., Luo, X., Mehboob, M. Z., Ao, T., and Lang, M. (2019). Identification and functional characterization of a novel selenocysteine methyltransferase from Brassica juncea L. J. Exp. Bot. 70, 6401-6416. doi: 10.1093/jxb/erz390

Cuderman, P., Kreft, I., Germ, M., Kovacevic, M., and Stibilj, V. (2008). Selenium species in selenium-enriched and drought-exposed potatoes. J. Agric. Food Chem. 56, 9114-9120. doi: 10.1021/jf8014969

Deng, X., Liu, K., Li, M., Zhang, W., Zhao, X., Zhao, Z., et al. (2017). Difference of selenium uptake and distribution in the plant and selenium form in the grains of rice with foliar spray of selenite or selenate at different stages. Field Crop Res. 211, 165-171. doi: 10.1016/j.fcr.2017.06.008

Dinh, Q. T., Wang, M., Tran, T. A. T., Zhou, F., Wang, D., Zhai, H., et al. (2019). Bioavailability of selenium in soil-plant system and a regulatory approach. Crit. Rev. Environ. Sci. Technol. 49, 443-517. doi: 10.1080/10643389.2018.1550987

do Nascimento da Silva, E., Aureli, F., D'Amato, M., Raggi, A., Cadore, S., and Cubadda, F. (2017). Selenium bioaccessibility and speciation in seleniumenriched lettuce: investigation of the selenocompounds liberated after in vitro simulated human digestion using two-dimensional HPLC-ICP-MS. J. Agric. Food Chem. 65, 3031-3038. doi: 10.1021/acs.jafc.7b01188

Dong, Z., Xiao, Y., and Wu, H. (2021). Selenium accumulation, speciation, and its effect on nutritive value of Flammulina velutipes (Golden needle mushroom). Food Chem. 350:128667. doi: 10.1016/j.foodchem.2020.128667

Duncan, E. G., Maher, W. A., Jagtap, R., Krikowa, F., Roper, M. M., and O'Sullivan, C. A. (2017). Selenium speciation in wheat grain varies in the presence of nitrogen and sulphur fertilisers. Environ. Geochem. Health 39, 955-966. doi: 10.1007/s10653-016-9857-6

Durán, P., Acuña, J., Armada, E., López-Castillo, O., Cornejo, P., Mora, M., et al. (2016). Inoculation with selenobacteria and arbuscular mycorrhizal fungi to enhance selenium content in lettuce plants and improve tolerance against drought stress. J. Soil Sci. Plant Nutr. 16, 211-225. doi: 10.4067/ S0718-95162016005000017

Durán, P., Acuña, J., Gianfreda, L., Azcón, R., Funes-Collado, V., and Mora, M. (2015). Endophytic selenobacteria as new inocula for selenium biofortification. Appl. Soil Ecol. 96, 319-326. doi: 10.1016/j.apsoil.2015.08.016 
Durán, P., Acuña, J., Jorquera, M., Azcón, R., Borie, F., Cornejo, P., et al. (2013). Enhanced selenium content in wheat grain by co-inoculation of selenobacteria and arbuscular mycorrhizal fungi: A preliminary study as a potential Se biofortification strategy. J. Cereal Sci. 57, 275-280. doi: 10.1016/j. jcs.2012.11.012

Durán, P., Acuña, J. J., Jorquera, M. A., Azcón, R., Paredes, C., Rengel, Z., et al. (2014). Endophytic bacteria from selenium-supplemented wheat plants could be useful for plant-growth promotion, biofortification and Gaeumannomyces graminis biocontrol in wheat production. Biol. Fertil. Soils 50, 983-990. doi: 10.1007/s00374-014-0920-0

Ebrahimi, N., Hartikainen, H., Hajiboland, R., and Seppänen, M. M. (2019). Uptake and remobilization of selenium in Brassica napus L. plants supplied with selenate or selenium-enriched plant residues. J. Plant Nutr. Soil Sci. 182, 196-202. doi: 10.1002/jpln.201700316

Ebrahimi, N., Hartikainen, H., Simojoki, A., Hajiboland, R., and Seppanen, M. (2015). Dynamics of dry matter and selenium accumulation in oilseed rape (Brassica napus L.) in response to organic and inorganic selenium treatments. Agric. Food Sci. 24, 104-117. doi: 10.23986/afsci.48346

Eich-Greatorex, S., Sogn, T. A., Øgaard, A. F., and Aasen, I. (2007). Plant availability of inorganic and organic selenium fertiliser as influenced by soil organic matter content and pH. Nutr. Cycl. Agroecosyst. 79, 221-231. doi: 10.1007/s10705-007-9109-3

El Mehdawi, A. F., Jiang, Y., Guignardi, Z. S., Esmat, A., Pilon, M., Pilon-Smits, E. A., et al. (2018). Influence of sulfate supply on selenium uptake dynamics and expression of sulfate/selenate transporters in selenium hyperaccumulator and nonhyperaccumulator Brassicaceae. New Phytol. 217, 194-205. doi: 10.1111/ nph. 14838

Feist, L. J., and Parker, D. R. (2001). Ecotypic variation in selenium accumulation among populations of Stanleya pinnata. New Phytol. 149, 61-69. doi: 10.1046/j. 1469-8137.2001.00004.x

Finley, J. W. (2005). Selenium accumulation in plant foods. Nutr. Rev. 63, 196-202. doi: 10.1111/j.1753-4887.2005.tb00137.x

Frommer, W. B., Hummel, S., and Riesmeier, J. W. (1993). Expression cloning in yeast of a cDNA encoding a broad specificity amino acid permease from Arabidopsis thaliana. Proc. Natl. Acad. Sci. U. S. A. 90, 5944-5948. doi: 10.1073/pnas.90.13.5944

Funes-Collado, V., Morell-Garcia, A., Rubio, R., and López-Sánchez, J. F. (2013). Study of selenocompounds from selenium-enriched culture of edible sprouts. Food Chem. 141, 3738-3743. doi: 10.1016/j.foodchem.2013.06.090

Gao, J., Liu, Y., Huang, Y., Lin, Z.-Q., Bañuelos, G. S., Lam, M. H.-W., et al. (2011). Daily selenium intake in a moderate selenium deficiency area of Suzhou, China. Food Chem. 126, 1088-1093. doi: 10.1016/j.foodchem.2010.11.137

Garneau, M. G., Tan, Q., and Tegeder, M. (2018). Function of pea amino acid permease AAP6 in nodule nitrogen metabolism and export, and plant nutrition. J. Exp. Bot. 69, 5205-5219. doi: 10.1093/jxb/ery289

Garousi, F., Kovács, B., Domokos-Szabolcsy, É., and Veres, S. (2017). Biological changes of green pea (Pisum sativum L.) by selenium enrichment. Acta Biol. Hung. 68, 60-72. doi: 10.1556/018.68.2017.1.6

Guignardi, Z., and Schiavon, M. (2017). "Biochemistry of plant selenium uptake and metabolism," in Selenium in Plants. eds. E. A. H. Pilon-Smits, L. H. E. Winkel and Z-Q. Lin (Cham, Switzerland: Springer), 21-34.

Guo, N., Hu, J., Yan, M., Qu, H., Luo, L., Tegeder, M., et al. (2020a). Oryza sativa lysine-histidine-type transporter 1 functions in root uptake and rootto-shoot allocation of amino acids in rice. Plant J. 103, 395-411. doi: 10.1111/ tpj. 14742

Guo, Y., Luo, Y., Wang, N., Tang, M., Xiao, J., Chen, S.-W., et al. (2020b). Au nanoparticle-based probe for selenol in living cells and selenium-rich tea and rice. Talanta 212:120583. doi: 10.1016/j.talanta.2019.120583

Hawrylak-Nowak, B. (2013). Comparative effects of selenite and selenate on growth and selenium accumulation in lettuce plants under hydroponic conditions. Plant Growth Regul. 70, 149-157. doi: 10.1007/s10725-013-9788-5

Hoffman, K. S., Vargas-Rodriguez, O., Bak, D. W., Mukai, T., Woodward, L. K., Weerapana, E., et al. (2019). A cysteinyl-tRNA synthetase variant confers resistance against selenite toxicity and decreases selenocysteine misincorporation. J. Biol. Chem. 294, 12855-12865. doi: 10.1074/jbc. RA119.008219

Hu, T., Hui, G., Li, H., and Guo, Y. (2020). Selenium biofortification in Hericium erinaceus (Lion's Mane mushroom) and its in vitro bioaccessibility. Food Chem. 331:127287. doi: 10.1016/j.foodchem.2020.127287
Hu, T., Li, H., Li, J., Zhao, G., Wu, W., Liu, L., et al. (2018). Absorption and bio-transformation of selenium nanoparticles by wheat seedlings (Triticum aestivum L.). Front. Plant Sci. 9:597. doi: 10.3389/fpls.2018.00597

$\mathrm{Hu}, \mathrm{T} ., \mathrm{Li}, \mathrm{H} ., \mathrm{Zhao}$ G., and Guo, Y. (2021a). Selenium enriched Hypsizygus marmoreus, a potential food supplement with improved Se bioavailability. LWT 140:110819. doi: 10.1016/j.lwt.2020.110819

Hu, Z., Yao, Y., Lv, M., Zhang, Y., Zhang, L., Yuan, Y., et al. (2021b). Isolation and identification of three water-soluble selenoproteins in Se-enriched Agaricus blazei Murrill. Food Chem. 344:128691. doi: 10.1016/j.foodchem.2020.128691

Huang, Y., Wang, Q., Gao, J., Lin, Z., Banuelos, G. S., Yuan, L., et al. (2013). Daily dietary selenium intake in a high selenium area of Enshi, China. Nutrients 5, 700-710. doi: 10.3390/nu5030700

Huang, Q. Q., Wang, Q., Wan, Y., Yu, Y., Jiang, R., and Li, H. (2017). Application of X-ray absorption near edge spectroscopy to the study of the effect of sulphur on selenium uptake and assimilation in wheat seedlings. Biol. Plant. 61, 726-732. doi: 10.1007/s10535-016-0698-Z

Huysen, T. V., Abdel-Ghany, S., Hale, K., LeDuc, D., Terry, N., and Pilon-Smits, E. H. (2003). Overexpression of cystathionine- $\gamma$-synthase enhances selenium volatilization in Brassica juncea. Planta 218, 71-78. doi: 10.1007/ s00425-003-1070-z

Huysen, T., Terry, N., and Pilon-Smits, E. (2004). Exploring the selenium phytoremediation potential of transgenic Indian mustard overexpressing ATP sulfurylase or cystathionine- $\gamma$-synthase. Int. J. Phytoremediation 6, 111-118. doi: 10.1080/16226510490454786

Ip, C., Birringer, M., Block, E., Kotrebai, M., Tyson, J. F., Uden, P. C., et al. (2000). Chemical speciation influences comparative activity of seleniumenriched garlic and yeast in mammary cancer prevention. J. Agric. Food Chem. 48, 2062-2070. doi: 10.1021/jf000051f

Jähne, F., Hahn, V., Würschum, T., and Leiser, W. L. (2020). Speed breeding short-day crops by LED-controlled light schemes. Theor. Appl. Genet. 133, 2335-2342. doi: 10.1007/s00122-020-03601-4

Jiang, L., Cao, H., Chen, Z., Liu, C., Cao, S., Wei, Z., et al. (2018). Cytokinin is involved in TPS22-mediated selenium tolerance in Arabidopsis thaliana. Ann. Bot. 122, 501-512. doi: 10.1093/aob/mcy093

Kápolna, E., Hillestrøm, P. R., Laursen, K. H., Husted, S., and Larsen, E. H. (2009). Effect of foliar application of selenium on its uptake and speciation in carrot. Food Chem. 115, 1357-1363. doi: 10.1016/j. foodchem.2009.01.054

Kikkert, J., and Berkelaar, E. (2013). Plant uptake and translocation of inorganic and organic forms of selenium. Arch. Environ. Contam. Toxicol. 65, 458-465. doi: 10.1007/s00244-013-9926-0

Kotrebai, M., Birringer, M., Tyson, J. F., Block, E., and Uden, P. C. (2000). Selenium speciation in enriched and natural samples by HPLC-ICP-MS and HPLC-ESI-MS with perfluorinated carboxylic acid ion-pairing agents presented at SAC 99, Dublin, Ireland, July 25-30, 1999. Analyst 125, 71-78. doi: $10.1039 / \mathrm{a} 906320 \mathrm{j}$

Li, Z., Liang, D., Peng, Q., Cui, Z., Huang, J., and Lin, Z. (2017). Interaction between selenium and soil organic matter and its impact on soil selenium bioavailability: a review. Geoderma 295, 69-79. doi: 10.1016/j. geoderma.2017.02.019

Li, H. F., McGrath, S. P., and Zhao, F. J. (2008). Selenium uptake, translocation and speciation in wheat supplied with selenate or selenite. New Phytol. 178, 92-102. doi: 10.1111/j.1469-8137.2007.02343.X

Li, X., Wu, Y., Li, B., Yang, Y., and Yang, Y. (2018a). Selenium accumulation characteristics and biofortification potentiality in turnip (Brassica rapa var. rapa) supplied with selenite or selenate. Front. Plant Sci. 8:2207. doi: 10.3389/ fpls.2017.02207

Li, M., Zhao, Z., Zhou, J., Zhou, D., Chen, B., Huang, L., et al. (2018b). Effects of a foliar spray of selenite or selenate at different growth stages on selenium distribution and quality of blueberries. J. Sci. Food Agric. 98, 4700-4706. doi: $10.1002 /$ jsfa.9004

Li, Y., Zhu, N., Liang, X., Zheng, L., Zhang, C., Li, Y.-F., et al. (2020). A comparative study on the accumulation, translocation and transformation of selenite, selenate, and SeNPs in a hydroponic-plant system. Ecotoxicol. Environ. Saf. 189:109955. doi: 10.1016/j.geoderma.2017.02.019

Lima, L. W., Pilon-Smits, E. A., and Schiavon, M. (2018). Mechanisms of selenium hyperaccumulation in plants: a survey of molecular, biochemical and ecological cues. Biochim. Biophys. Acta 1862, 2343-2353. doi: 10.1016/j. bbagen.2018.03.028 
Liu, H., Yu, F., Shao, W., Ding, D., Yu, Z., Chen, F., et al. (2018). Associations between selenium content in hair and Kashin-Beck disease/Keshan disease in children in northwestern China: a prospective cohort study. Biol. Trace Elem. Res. 184, 16-23. doi: 10.1007/s12011-017-1169-x

Longchamp, M., Angeli, N., and Castrec-Rouelle, M. (2013). Selenium uptake in Zea mays supplied with selenate or selenite under hydroponic conditions. Plant Soil 362, 107-117. doi: 10.1007/s11104-012-1259-7

Lyi, S. M., Heller, L. I., Rutzke, M., Welch, R. M., Kochian, L. V., and Li, L. (2005). Molecular and biochemical characterization of the selenocysteine Se-methyltransferase gene and Se-methylselenocysteine synthesis in broccoli. Plant Physiol. 138, 409-420. doi: 10.1104/pp.104.056549

Mahood, E. H., Kruse, L. H., and Moghe, G. D. (2020). Machine learning: a powerful tool for gene function prediction in plants. Appl. Plant Sci. 8:e11376. doi: 10.1002/aps3.11376

Malagoli, M., Schiavon, M., and Pilon-Smits, E. A. (2015). Effects of selenium biofortification on crop nutritional quality. Front. Plant Sci. 6:280. doi: 10.3389/fpls.2015.00280

Mechora, Š., Germ, M., and Stibilj, V. (2012). Selenium compounds in seleniumenriched cabbage. Pure Appl. Chem. 84, 259-268. doi: 10.1351/PACCON-11-07-19

Milovanovic, I., Lajin, B., Braeuer, S., Steiner, O., Lisa, F., and Goessler, W. (2019). Simultaneous selenium and sulfur speciation analysis in cultivated Pleurotus pulmonarius mushroom. Food Chem. 279, 231-236. doi: 10.1016/j. foodchem.2018.12.009

Muzembo, B. A., Ngatu, N. R., Januka, K., Huang, H.-L., Nattadech, C., Suzuki, T., et al. (2019). Selenium supplementation in HIV-infected individuals: a systematic review of randomized controlled trials. Clin. Nutr. ESPEN 34, 1-7. doi: 10.1016/j.clnesp.2019.09.005

Nakamaru, Y. M., and Altansuvd, J. (2014). Speciation and bioavailability of selenium and antimony in non-flooded and wetland soils: a review. Chemosphere 111, 366-371. doi: 10.1016/j.chemosphere.2014.04.024

National Health Commission (2018). Chinese dietary reference intakes. (WS/T 578.5-2018). People's Republic of China National Health Commission. Available at: http://www.nhc.gov.cn/wjw/yingyang/wsbz.shtml (Accessed January 2, 2022).

Nie, Z., Zhu, J., Li, J., Liu, H., Zhao, P., Gao, W., et al. (2020). Phosphorus application alters concentrations and proportions of organic Se forms in the grain of winter wheat. J. Plant Nutr. Soil Sci. 183, 282-291. doi: 10.1002/ jpln.201900045

Niu, J., Liu, C., Huang, M., Liu, K., and Yan, D. (2021). Effects of foliar fertilization: a review of current status and future perspectives. J. Soil Sci. Plant Nutr. 21, 104-118. doi: 10.1007/s42729-020-00346-3

Ogra, Y., Ogihara, Y., and Anan, Y. (2017). Comparison of the metabolism of inorganic and organic selenium species between two selenium accumulator plants, garlic and Indian mustard. Metallomics 9, 61-68. doi: 10.1039/c6mt00128a

Palomo-Siguero, M., López-Heras, M. I., Cámara, C., and Madrid, Y. (2015). Accumulation and biotransformation of chitosan-modified selenium nanoparticles in exposed radish (Raphanus sativus). J. Anal. Atom. Spectrom. 30, 1237-1244. doi: 10.1039/C4JA00407H

Pedrero, Z., and Madrid, Y. (2009). Novel approaches for selenium speciation in foodstuffs and biological specimens: a review. Anal. Chim. Acta 634, 135-152. doi: 10.1016/j.aca.2008.12.026

Piekarska, A., Kołodziejski, D., Pilipczuk, T., Bodnar, M., Konieczka, P., Kusznierewicz, B., et al. (2014). The influence of selenium addition during germination of Brassica seeds on health-promoting potential of sprouts. Int. J. Food Sci. Nutr. 65, 692-702. doi: 10.3109/09637486.2014.917148

Pilon-Smits, E. A. (2017). "Mechanisms of plant selenium hyperaccumulation," in Selenium in Plants. eds. E. A. H. Pilon-Smits, L. H. E. Winkel and Z-Q. Lin (Cham, Switzerland: Springer), 53-66.

Poblaciones, M. J., Rodrigo, S., Santamaria, O., Chen, Y., and McGrath, S. P. (2014). Selenium accumulation and speciation in biofortified chickpea (Cicer arietinum L.) under Mediterranean conditions. J. Sci. Food Agric. 94, 1101-1106. doi: $10.1002 /$ jsfa.6372

Ponton, D. E., Fortin, C., and Hare, L. (2018). Organic selenium, selenate, and selenite accumulation by lake plankton and the alga Chlamydomonas reinhardtii at different $\mathrm{pH}$ and sulfate concentrations. Environ. Toxicol. Chem. 37, 2112-2122. doi: $10.1002 /$ etc. 4158

Pyrzynska, K., and Sentkowska, A. (2021). Selenium in plant foods: speciation analysis, bioavailability, and factors affecting composition. Crit. Rev. Food Sci. Nutr. 61, 1340-1352. doi: 10.1080/10408398.2020.1758027
Qin, H. B., Zhu, J. M., Lin, Z. Q., Xu, W. P., Tan, D. C., Zheng, L. R., et al. (2017). Selenium speciation in seleniferous agricultural soils under different cropping systems using sequential extraction and X-ray absorption spectroscopy. Environ. Pollut. 225, 361-369. doi: 10.1016/j.envpol.2017.02.062

Ramos, S. J., Yuan, Y., Faquin, V., Guilherme, L. R. G., and Li, L. (2011). Evaluation of genotypic variation of broccoli (Brassica oleracea var. italic) in response to selenium treatment. J. Agric. Food Chem. 59, 3657-3665. doi: $10.1021 /$ jf104731f

Rayman, M. P. (2012). Selenium and human health. Lancet 379, 1256-1268. doi: 10.1016/S0140-6736(11)61452-9

Rayman, M. P., Winther, K. H., Pastor-Barriuso, R., Cold, F., Thvilum, M., Stranges, S., et al. (2018). Effect of long-term selenium supplementation on mortality: results from a multiple-dose, randomised controlled trial. Free Radic. Biol. Med. 127, 46-54. doi: 10.1016/j.freeradbiomed.2018.02.015

Rees, K., Hartley, L., Day, C., Flowers, N., Clarke, A., and Stranges, S. (2013). Selenium supplementation for the primary prevention of cardiovascular disease. Cochrane Database Syst. Rev. 2013:CD009671. doi: 10.1002/14651858. CD009671.pub2

Renkema, H., Koopmans, A., Kersbergen, L., Kikkert, J., Hale, B., and Berkelaar, E. (2012). The effect of transpiration on selenium uptake and mobility in durum wheat and spring canola. Plant Soil 354, 239-250. doi: 10.1007/ s11104-011-1069-3

Rentsch, D., Schmidt, S., and Tegeder, M. (2007). Transporters for uptake and allocation of organic nitrogen compounds in plants. FEBS Lett. 581, 2281-2289. doi: 10.1016/j.febslet.2007.04.013

Sandholm, M., Oksanen, H., and Pesonen, L. (1973). Uptake of selenium by aquatic organisms. Limnol. Oceanogr. 18, 496-499. doi: 10.4319/ lo.1973.18.3.0496

Schiavon, M., Berto, C., Malagoli, M., Trentin, A., Sambo, P., Dall'Acqua, S., et al. (2016). Selenium biofortification in radish enhances nutritional quality via accumulation of methyl-selenocysteine and promotion of transcripts and metabolites related to glucosinolates, phenolics, and amino acids. Front. Plant Sci. 7:1371. doi: 10.3389/fpls.2016.01371

Schiavon, M., Pilon, M., Malagoli, M., and Pilon-Smits, E. A. (2015). Exploring the importance of sulfate transporters and ATP sulphurylases for selenium hyperaccumulation-a comparison of Stanleya pinnata and Brassica juncea (Brassicaceae). Front. Plant Sci. 6:2. doi: 10.3389/fpls.2015.00002

Shi, T., Wang, J., Chen, Y., and Wu, G. (2016). Improving the prediction of arsenic contents in agricultural soils by combining the reflectance spectroscopy of soils and rice plants. Int. J. Appl. Earth Obs. 52, 95-103. doi: 10.1016/j.jag.2016.06.002

Shreenath, A. P., Ameer, M. A., and Dooley, J. (2018). Selenium deficiency. Available at: https://europepmc.org/article/nbk/nbk482260\#free-full-text (Accessed January 2, 2022).

Šindelářová, K., Száková, J., Tremlová, J., Mestek, O., Praus, L., Kaňa, A., et al. (2015). The response of broccoli (Brassica oleracea convar. Italica) varieties on foliar application of selenium: uptake, translocation, and speciation. Food Addit. Contam. 32, 2027-2038. doi: 10.1080/19440049.2015.1099744

Skalickova, S., Milosavljevic, V., Cihalova, K., Horky, P., Richtera, L., and Adam, V. (2017). Selenium nanoparticles as a nutritional supplement. Nutrition 33, 83-90. doi: 10.1016/j.nut.2016.05.001

Song, Z., Shao, H., Huang, H., Shen, Y., Wang, L., Wu, F., et al. (2017). Overexpression of the phosphate transporter gene OsPT8 improves the $\mathrm{Pi}$ and selenium contents in Nicotiana tabacum. Environ. Exp. Bot. 137, 158-165. doi: 10.1016/j.envexpbot.2017.02.011

Sors, T. G., Martin, C. P., and Salt, D. E. (2009). Characterization of selenocysteine methyltransferases from Astragalus species with contrasting selenium accumulation capacity. Plant J. 59, 110-122. doi: 10.1111/j.1365-313X.2009.03855.x

Stavridou, E., Thorup-Kristensen, K., and Young, S. D. (2011). Assessment of selenium mineralization and availability from catch crops. Soil Use Manag. 27, 305-311. doi: 10.1111/j.1475-2743.2011.00343.x

Stranges, S., Marshall, J. R., Natarajan, R., Donahue, R. P., Trevisan, M., Combs, G. F., et al. (2007). Effects of long-term selenium supplementation on the incidence of type 2 diabetes: a randomized trial. Ann. Intern. Med. 147, 217-223. doi: 10.7326/0003-4819-147-4-200708210-00175

Tan, L. C., Nancharaiah, Y. V., van Hullebusch, E. D., and Lens, P. N. (2016). Selenium: environmental significance, pollution, and biological treatment technologies. Biotechnol. Adv. 34, 886-907. doi: 10.1016/j.biotechadv.2016.05.005

Terry, N., Zayed, A., De Souza, M., and Tarun, A. (2000). Selenium in higher plants. Annu. Rev. Plant Biol. 51, 401-432. doi: 10.1146/annurev.arplant.51.1.401 
Thosaikham, W., Jitmanee, K., Sittipout, R., Maneetong, S., Chantiratikul, A., and Chantiratikul, P. (2014). Evaluation of selenium species in seleniumenriched pakchoi (Brassica chinensis Jusl var parachinensis (Bailey) Tsen \& Lee) using mixed ion-pair reversed phase HPLC-ICP-MS. Food Chem. 145, 736-742. doi: 10.1016/j.foodchem.2013.08.116

United States Department of Agriculture Food Data Central Database (2021). Available at: https://fdc.nal.usda.gov (Accessed December 7, 2021).

Van Hoewyk, D., Garifullina, G. F., Ackley, A. R., Abdel-Ghany, S. E., Marcus, M. A., Fakra, S., et al. (2005). Overexpression of AtCpNifS enhances selenium tolerance and accumulation in Arabidopsis. Plant Physiol. 139, 1518-1528. doi: $10.1104 / p p .105 .068684$

Vinceti, M., Chiari, A., Eichmüller, M., Rothman, K. J., Filippini, T., Malagoli, C., et al. (2017b). A selenium species in cerebrospinal fluid predicts conversion to Alzheimer's dementia in persons with mild cognitive impairment. Alzheimers Res. Ther. 9, 1-11. doi: 10.1186/s13195-017-0323-1

Vinceti, M., Filippini, T., Cilloni, S., Bargellini, A., Vergoni, A. V., Tsatsakis, A., et al. (2017a). Health risk assessment of environmental selenium: emerging evidence and challenges. Mol. Med. Rep. 15, 3323-3335. doi: 10.3892/ mmr.2017.6377

Vinceti, M., Filippini, T., and Rothman, K. J. (2018). Selenium exposure and the risk of type 2 diabetes: a systematic review and meta-analysis. Eur. J. Epidemiol. 33, 789-810. doi: 10.1007/s10654-018-0422-8

Wadhwani, S. A., Shedbalkar, U. U., Singh, R., and Chopade, B. A. (2016). Biogenic selenium nanoparticles: current status and future prospects. Appl. Microbiol. Biotechnol. 100, 2555-2566. doi: 10.1007/s00253-016-7300-7

Wang, M., Ali, F., Qi, M., Peng, Q., Wang, M., Bañuelos, G. S., et al. (2021). Insights into uptake, accumulation, and subcellular distribution of selenium among eight wheat (Triticum aestivum L.) cultivars supplied with selenite and selenate. Ecotoxicol. Environ. Saf. 207:111544. doi: 10.1016/j. ecoenv.2020.111544

Wang, M., Ali, F., Wang, M., Dinh, Q. T., Zhou, F., Bañuelos, G. S., et al. (2020b). Understanding boosting selenium accumulation in wheat (Triticum aestivum $\mathrm{L}$.) following foliar selenium application at different stages, forms, and doses. Environ. Sci. Pollut. Res. 27, 717-728. doi: 10.1007/ s11356-019-06914-0

Wang, D., Dinh, Q. T., Thu, T. T. A., Zhou, F., Yang, W., Wang, M., et al. (2018). Effect of selenium-enriched organic material amendment on selenium fraction transformation and bioavailability in soil. Chemosphere 199, 417-426. doi: 10.1016/j.chemosphere.2018.02.007

Wang, K., Wang, Y., Li, K., Wan, Y., Wang, Q., Zhuang, Z., et al. (2020a). Uptake, translocation and biotransformation of selenium nanoparticles in rice seedlings (Oryza sativa L.). J. Nanobiotechnol. 18, 1-15. doi: 10.1186/ s12951-020-00659-6

Wang, Y.-D., Wang, X., and Wong, Y.-S. (2013). Generation of selenium-enriched rice with enhanced grain yield, selenium content and bioavailability through fertilisation with selenite. Food Chem. 141, 2385-2393. doi: 10.1016/j. foodchem.2013.05.095

Wichman, J., Winther, K. H., Bonnema, S. J., and Hegedüs, L. (2016). Selenium supplementation significantly reduces thyroid autoantibody levels in patients with chronic autoimmune thyroiditis: a systematic review and meta-analysis. Thyroid 26, 1681-1692. doi: 10.1089/thy.2016.0256

Wiesner-Reinhold, M., Schreiner, M., Baldermann, S., Schwarz, D., Hanschen, F. S., Kipp, A. P., et al. (2017). Mechanisms of selenium enrichment and measurement in Brassicaceous vegetables, and their application to human health. Front. Plant Sci. 8:1365. doi: 10.3389/fpls.2017.01365

Winkel, L. H., Johnson, C. A., Lenz, M., Grundl, T., Leupin, O. X., Amini, M., et al. (2012). Environmental selenium research: from microscopic processes to global understanding. Environ. Sci. Technol. 46, 571-579. doi: 10.1021/ es $203434 \mathrm{~d}$

Wu, Z., Bañuelos, G. S., Lin, Z.-Q., Liu, Y., Yuan, L., Yin, X., et al. (2015). Biofortification and phytoremediation of selenium in China. Front. Plant Sci. 6:136. doi: $10.3389 /$ fpls.2015.00136

Wu, X., Tao, M., Meng, Y., Zhu, X., Qian, L., Shah, A., et al. (2020). The role of WRKY47 gene in regulating selenium tolerance in Arabidopsis thaliana. Plant Biotechnol. Rep. 14, 121-129. doi: 10.1007/s11816-019-00560-1

Xie, M., Sun, X., Li, P., Shen, X., and Fang, Y. (2021). Selenium in cereals: insight into species of the element from total amount. Compr. Rev. Food Sci. Food Saf. 20, 2914-2940. doi: 10.1111/1541-4337.12748
Yang, X., Gil, M. I., Yang, Q., and Tomás-Barberán, F. A. (2021). Bioactive compounds in lettuce: highlighting the benefits to human health and impacts of preharvest and postharvest practices. Compr. Rev. Food Sci. Food Saf. 1-42. doi: 10.1111/1541-4337.12877

Yang, G., Wei, Q., Huang, H., and Xia, J. (2020). Amino acid transporters in plant cells: a brief review. Plan. Theory 9:967. doi: 10.3390/plants9080967

Yin, H., Qi, Z., Li, M., Ahammed, G. J., Chu, X., and Zhou, J. (2019). Selenium forms and methods of application differentially modulate plant growth, photosynthesis, stress tolerance, selenium content and speciation in Oryza sativa L. Ecotoxicol. Environ. Saf. 169, 911-917. doi: 10.1016/j.ecoenv.2018.11.080

Yoosefzadeh-Najafabadi, M., Earl, H. J., Tulpan, D., Sulik, J., and Eskandari, M. (2021). Application of machine learning algorithms in plant breeding: predicting yield from hyperspectral reflectance in soybean. Front. Plant Sci. 11:624273. doi: $10.3389 /$ fpls.2020.624273

Yu, D., Liang, D., Lei, L., Zhang, R., Sun, X., and Lin, Z. (2015). Selenium geochemical distribution in the environment and predicted human daily dietary intake in northeastern Qinghai, China. Environ. Sci. Pollut. Res. 22, 11224-11235. doi: 10.1007/s11356-015-4310-4

Yu, Y., Liu, Z., Luo, L.-Y., Fu, P.-N., Wang, Q., and Li, H.-F. (2019). Selenium uptake and biotransformation in Brassica rapa supplied with selenite and selenate: a hydroponic work with HPLC speciation and RNA-sequencing. J. Agric. Food Chem. 67, 12408-12418. doi: 10.1021/acs.jafc.9b05359

Yuan, L., Yin, X., Zhu, Y., Li, F., Huang, Y., Liu, Y., et al. (2012). "Selenium in plants and soils, and selenosis in Enshi, China: implications for selenium biofortification," in Phytoremediation and Biofortification. eds. X. Yin and L. Yuan (Dordrecht, Netherlands: Springer), 7-31.

Zhang, M., Pang, Y., Yi, Q., Huang, J., Huang, X., Huang, Q., et al. (2020). Comparative effectiveness of Se translocation between low-Se and high-Se rice cultivars under Se fertilization. Ecotoxicol. Environ. Saf. 205:111372. doi: $10.1016 /$ j.ecoenv.2020.111372

Zhang, X., Wang, T., Li, S., Ye, C., Hou, J., Li, Q., et al. (2019a). A spatial ecology study of Keshan disease and hair selenium. Biol. Trace Elem. Res. 189, 370-378. doi: 10.1007/s12011-018-1495-7

Zhang, L.-H., Wei-Ming, S., and Xiao-Chang, W. (2006). Difference in selenium accumulation in shoots of two rice cultivars. Pedosphere 16, 646-653. doi: 10.1016/S1002-0160(06)60098-2

Zhang, M., Xing, G., Tang, S., Pang, Y., Yi, Q., Huang, Q., et al. (2019c). Improving soil selenium availability as a strategy to promote selenium uptake by high-Se rice cultivar. Environ. Exp. Bot. 163, 45-54. doi: 10.1016/j.envexpbot.2019.04.008

Zhang, H., Zhao, Z., Zhang, X., Zhang, W., Huang, L., Zhang, Z., et al. (2019b). Effects of foliar application of selenate and selenite at different growth stages on selenium accumulation and speciation in potato (Solanum tuberosum L.). Food Chem. 286, 550-556. doi: 10.1016/j.foodchem.2019.01.185

Zhou, F., Yang, W., Wang, M., Miao, Y., Cui, Z., Li, Z., et al. (2018). Effects of selenium application on Se content and speciation in Lentinula edodes. Food Chem. 265, 182-188. doi: 10.1016/j.foodchem.2018.05.087

Zhou, X., Yuan, Y., Yang, Y., Rutzke, M., Thannhauser, T. W., Kochian, L. V., et al. (2009). Involvement of a broccoli COQ5 methyltransferase in the production of volatile selenium compounds. Plant Physiol. 151, 528-540. doi: $10.1104 /$ pp.109.142521

Conflict of Interest: The authors declare that the research was conducted in the absence of any commercial or financial relationships that could be construed as a potential conflict of interest.

Publisher's Note: All claims expressed in this article are solely those of the authors and do not necessarily represent those of their affiliated organizations, or those of the publisher, the editors and the reviewers. Any product that may be evaluated in this article, or claim that may be made by its manufacturer, is not guaranteed or endorsed by the publisher.

Copyright (๑) $2022 \mathrm{Hu}$, Wang, Zhang, Peng, Huang, Yang, Jeong and Yang. This is an open-access article distributed under the terms of the Creative Commons Attribution License (CC BY). The use, distribution or reproduction in other forums is permitted, provided the original author(s) and the copyright owner(s) are credited and that the original publication in this journal is cited, in accordance with accepted academic practice. No use, distribution or reproduction is permitted which does not comply with these terms. 